\title{
Equitable utilisation of Indian community based health insurance scheme among its rural membership: cluster randomised controlled trial
}

\author{
M Kent Ranson, lecturer in health economics, ${ }^{1}$ Tara Sinha, research coordinator, ${ }^{3}$ \\ Mirai Chatterjee, coordinator, SEWA social security, ${ }^{3}$ Fenil Gandhi, research and programme associate, ${ }^{3}$ \\ Rupal Jayswal, research and programme associate, ${ }^{3}$ Falguni Patel, research and programme associate, ${ }^{3}$ \\ Saul S Morris, honorary senior lecturer, ${ }^{2}$ Anne J Mills professor of health economics and policy ${ }^{1}$
}

1Health Economics and Financing Programme, Health Policy Unit, London School of Hygiene and Tropical Medicine, London WC1E 7HT

${ }^{2}$ Nutrition and Public Health Intervention Research Unit, London School of Hygiene and Tropical Medicine

${ }^{3}$ SEWA Reception Centre, Bhadra Ahmedabad, India 380001

Correspondence to: M K Ranson kent.ranson@lshtm.ac.uk

doi: 10.1136/bmj.39192.719583.AE

\section{ABSTRACT}

Objective To evaluate alternative strategies for improving the uptake of benefits of a community based health insurance scheme by its poorest members.

Design Prospective cluster randomised controlled trial. Setting Self Employed Women's Association (SEWA) community based health insurance scheme in rural India. Participants 713 claimants at baseline (2003) and 1440 claimants two years later among scheme members in 16 rural sub-districts.

Interventions After sales service with supportive supervision, prospective reimbursement, both packages, and neither package, randomised by sub-district.

Main outcome measures The primary outcome was socioeconomic status of claimants relative to members living in the same sub-district. Secondary outcomes were enrolment rates in SEWA Insurance, mean socioeconomic status of the insured population relative to the general rural population, and rate of claim submission.

Results Between 2003 and 2005, the mean socioeconomic status of SEWA Insurance members (relative to the rural population of Gujarat) increased significantly. Rates of claims also increased significantly, on average by 21.6 per 1000 members ( $\mathrm{P}<0.001)$.

However, differences between the intervention groups and the standard scheme were not significant. No systematic effect of time or interventions on the socioeconomic status of claimants relative to members in the same sub-district was found

Conclusions Neither intervention was sufficient to ensure that the poorer members in each sub-district were able to enjoy the greater share of the scheme benefits. Claim submission increased as a result of interventions that seem to have strengthened awareness of and trust in a community based health insurance scheme.

Trial registration Clinical trials NCT00421629.

\section{INTRODUCTION}

Poor people in developing countries are less likely to seek care when sick than those who are better off..$^{1-3}$ The costs of care can drive the poor deeper into poverty. ${ }^{4}$ Community based health insurance can potentially protect people from healthcare costs and ensure equitable pooling of risk between richer and poorer, and sick and healthy, members. ${ }^{5}$ The World Health Organization has called for investigation of mechanisms to bring the poor into such schemes. ${ }^{6}$

Empirical evidence suggests, however, that the scope for equitable redistribution of resources through community based health insurance schemes is limited. Membership is generally small ${ }^{7}$; schemes cover on average around $10 \%$ of target populations. ${ }^{8}$ Community based health insurance has tended to exclude the poorest people from membership, ${ }^{910}$ generally charging a flat premium that is unaffordable. ${ }^{9}$ Within schemes, utilisation of health care may be inequitable (or equity neutral), although evidence is limited. Utilisation of health care by insured members has been found to be higher among households located close to health facilities, probably the better off ones. ${ }^{911}$ Studies in Rwanda and the Philippines found that utilisation by socioeconomic status was equity neutral among insured people and inequitable among uninsured people. $^{1213}$

According to WHO, more than $75 \%$ of total expenditure on health in India is private, ${ }^{14}$ and most of this flows directly from households in the form of out of pocket payments to the private, for profit healthcare sector. Because poor people lack the resources to pay for health care, they are far more likely than less poor people to avoid going for care or to become indebted or impoverished trying to pay for it. ${ }^{15}$ The richest fifth of the population are six times more likely than the poorest fifth to have been admitted to hospital, whether in the public or private sector. ${ }^{16}$ Peters and colleagues estimated that at least $24 \%$ of all Indians admitted to hospital fall below the poverty line because of their admission and that out of pocket spending on hospital care might have raised by two percentage points the proportion of the population in poverty. ${ }^{15}$ Less than $10 \%$ of the population (roughly 75 million people) are covered by some form of health insurance, and the vast majority of these are either civil servants or formal sector workers. ${ }^{1718}$ 
Debate continues as to whether insurance is a viable model for tackling the problems of limited access and medical indebtedness in poor communities in India. The World Health Report 2000 noted that prepayment schemes (including community based health insurance) represent the most effective way to protect people from the costs of health care and called for investigation into mechanisms to bring poor people into such schemes. ${ }^{6}$ India's National Health Policy (2002) encouraged the setting up of private insurance companies and the introduction of government funded district based insurance schemes on a pilot basis. ${ }^{19}$ Although the private insurance sector has grown tremendously in recent years and implementation of pilot district based schemes has increased, empirical data about the impact of insurance among poor communities are lacking. Evidence on community based health insurance schemes in India suggests that they tend to have limited coverage of the population and that the poorest people often find the premiums prohibitively expensive but that they do provide important financial protection among people who are able to enrol. ${ }^{20-22}$

We assessed interventions aimed at improving the distributional impact of a community based health insurance scheme in rural India, by means of a cluster randomised trial. We believe it to be the first study to examine whether community based health insurance schemes can be made more equitable in terms of improving the uptake of benefits by poorer members. Cluster randomised design is not uncontroversial for the evaluation of complex interventions, ${ }^{23}$ and we were interested in exploring the feasibility and value of such a design, ${ }^{24}$ as well as seeking to collect relevant data on context and processes. ${ }^{25-27}$

\section{METHODS}

Since 1992, the Self Employed Women's Association (SEWA) - a trade union of more than half a million poor women working in the informal sector and based in the Indian state of Gujarat-has been

\section{Table 1| Objectives of interventions, with corresponding functions and processes}

\section{Objectives of interventions \\ Functions and processes}

Standard scheme

To recruit members, and provide them with support between the annual enrolment campaigns

To provide aagewans with training and supervision.

To process members' hospital admission insurance claims

After sales service and supportive supervision

To improve members' understanding of the insurance (particularly the hospital admission component) and the requirements for making a claim

To ensure that members have ready access to the information needed to submit a claim

To ensure that after sales service is particularly strong among the poorest members

To provide aagewans with an increased level of support and supervision

To involve aagewans in developing the intervention in orderto $\mathrm{S}$ increase acceptability and sustainability

Prospective reimbursement

To direct members to inpatient facilities with acceptable levels of quality

To facilitate access to hospital admission by removing financial barriers

To make it easier to claim and receive benefits under the scheme

SEWA=Self Employed Women's Association.
Responsibility for compiling an insurance claim lies primarily with the insured members. Members are supposed to present the required documents to an aagewan or SEWA office in order to submit a claim. Not uncommonly, the aagewans help members to get the required documents if the member faces difficulty. Reimbursement of successful claims generally occurs between two weeks and two months after the claim is submitted to SEWA Insurance

House to house visits to members' homes are rarely made by SEWA Insurance aagewan. Refresher visits to villages during the nine month period between campaigns occur very infrequently. Insured members are not guided in terms of types of facilities that they should use if they need inpatient care

SEWA Insurance aagewans receive most of their supervision from district specific team leaders, in the setting of a weekly (or fortnightly) meeting, and they receive capacity building once every few months in the setting of cluster meetings, which bring together the aagewans of several districts. Rarely do they receive direct guidance in planning their village visits, direct together the aagewans of several districts. Rarely do they receive direct guidance in planning the

Aagewans will make house to house visits among all insured households, so that each member household is visited at least
twice after enrolment. Aagewans will provide information tailored to local language and culture

Members will periodically be provided with a wall piece reminding them of the insurance and providing a local contact telephone number. They will also be provided with a preaddressed, prestamped postcard that is to be mailed to SEWA Insurance if they need assistance or have a claim to submit

Equity sensitisation among aagewans, to include a participatory poverty mapping exercise in the sub-district to which the aagewan is assigned and ongoing reminders of the barriers that prevent the poorest members from availing themselves of the hospital admission benefits. Ensuring that house to house visits include (or focus on) the poorest members

Provide aagewans with a list of all members in their sub-district and their addresses. Jointly develop visit plans for house to house visits ("microplanning"). Monitor progress with the house to house visits by using bar codes (to be collected by aagewans at member household). Accompany aagewans on their house to house visits, intensively in the initial weeks and gradually reduced. Hold regular meetings with aagewans to review their work and build capacity. Periodic visits to randomly selected villages to seek community input on the performance of aagewans. This monitoring and accompanying will initially be done by the research team and will gradually be passed over to the operations team where staff are available

Self assessment exercises with aagewans to identify their training and information needs

A standardised procedure is developed for screening hospitals for inclusion in this scheme. Even after inclusion, hospital performance is periodically re-evaluated

Members are encouraged to use (relatively) low cost public and trust hospitals in (or near) their sub-district. For two such hospitals in each sub-district, mechanisms are developed so that $80 \%$ of the total, predicted cost of hospital admission is paid directly to the claimant within 48-72 hours of admission. The balance of the cost (up to 2000 rupees) will be paid to the claimant at the time of discharge from hospital, on the condition that relevant certificates and receipts are produced

Members will be reminded about the benefits of the hospital admission insurance and educated about prospective reimbursement in a campaign delivered by aagewans and staff of the research team. Responsibilities for compilation and submission of claims are (largely) shifted away from SEWA Insurance members (and their families) and on to SEWA staff 
providing insurance to its members and their families. The insurance is voluntary, combining insurance for assets, life, and hospital admission in a single policy. Women are the principal members and can also buy insurance for their husbands and children.

Most members - more than $97 \%$ of those who joined in 2003 - pay an annual premium of 85 rupees $(£ 1 ; € 1.5$; $\$ 2)$ for the least expensive policy. This covers the costs of inpatient care to a maximum of 2000 rupees a year. Members can also make a one time fixed deposit of 1000 rupees in SEWA Bank, and interest from this deposit is used to pay the annual premium. Members with fixed deposits account for roughly 30\% of current members. In 2003, SEWA Insurance had 101809 members in Gujarat state, two thirds of them (67 584) in rural areas and one third (33080) in Ahmedabad City. The scheme is run by a team of fulltime staff and local women leaders (aagewans), who form the critical link between members and scheme administrators.

Surveys in 2003 found that the poorest households in the general population were able to enrol in the scheme. ${ }^{28}$ In rural areas, for example, $32 \%$ of members were drawn from households below the 30th centile of socioeconomic status, and $8 \%$ of members were from the poorest tenth. The submission of claims for hospital admission was equitable in Ahmedabad City; however, in rural areas, financially better off members were significantly more likely to submit claims than were the poorest members. Qualitative research revealed that poor people faced barriers to accessing hospitals with inpatient facilities, such as lack of money to pay for the hospital admission or travel to hospital, ${ }^{29}$ and barriers to filing an insurance claim, such as lack of skills and capabilities, the costs of compiling a claim, and lack of cooperation from doctors.

On the basis of these insights, we developed and tested in a randomised trial the impact of two interventions that aimed to improve the equity of claims in rural areas. These interventions were after sales service and supportive supervision, and prospective reimbursement, implemented singly and together (table 1). After sales service and supportive supervision involved aagewans making house to house educational visits to SEWA Insurance members after enrolment and providing supportive supervision to the workers. In addition to education, households were provided with a reminder wall piece and a prestamped and preaddressed postcard for communicating with SE WA Insurance. Prospective reimbursement involved making arrangements with two hospitals in each subdistrict so that members could be reimbursed before discharge from hospital. In communities that received both interventions (the "both" intervention area), these were implemented simultaneously and in an integrated manner. To enhance the generalisability of our findings, we defined the interventions in terms of processes rather than simple elements. ${ }^{30}$ Thus, under the prospective reimbursement intervention, we improved financial access to hospital admission by developing mechanisms so that $80 \%$ of the predicted cost of hospital admission (up to a maximum of 1600 rupees) could be reimbursed within 48 hours of admission, but the specifics of the intervention-for example, the type of person responsible for paying the cash benefit—varied between sub-districts.

Assessing the effectiveness of such interventions is important to public health and health care in India

Table 2 | Household level data collection to assess primary outcome (socioeconomic status)

\begin{tabular}{|c|c|c|c|c|c|}
\hline Characteristic & $\begin{array}{l}\text { Survey of general, rural } \\
\text { population }\end{array}$ & Baseline member survey & Baseline claimant census & Follow-up member survey & Follow-up claimant census \\
\hline Sampling universe & $\begin{array}{l}\text { Households in } 11 \text { rural districts } \\
\text { (2001 population, } 19298638 \text { ) } \\
\text { from which SEWA Insurance } \\
\text { draws its members }\end{array}$ & $\begin{array}{l}36837 \text { adult female members } \\
\text { in } 2003 \text { who reside in } 16 \text { rural } \\
\text { sub-districts }\end{array}$ & $\begin{array}{l}713 \text { hospital admission claims, } \\
\text { January to September } 2003\end{array}$ & $\begin{array}{l}25497 \text { adult female members } \\
\text { in } 2005 \text { who reside in } 16 \text { rural } \\
\text { sub-districts }\end{array}$ & $\begin{array}{l}1440 \text { hospital admission } \\
\text { claims, April to December, } 2005\end{array}$ \\
\hline Intended sample size & 800 & 1200 & 713 & 1200 & 1440 \\
\hline Sampling method & Two stage random sampling & $\begin{array}{l}\text { Two stage random sampling, } \\
\text { stratified by sub-district }\end{array}$ & NA (all claimants interviewed) & $\begin{array}{l}\text { Two stage random sampling, } \\
\text { stratified by sub-district }\end{array}$ & NA (all claimants interviewed) \\
\hline $\begin{array}{l}\text { Sampling at first } \\
\text { stage }\end{array}$ & $\begin{array}{l}\text { Towns/villages sampled with } \\
\text { PPS }\end{array}$ & $\begin{array}{l}\text { Villages (or clusters of villages) } \\
\text { sampled with PPS }\end{array}$ & NA & $\begin{array}{l}\text { Villages (or clusters of villages) } \\
\text { sampled with PPS }\end{array}$ & NA \\
\hline $\begin{array}{l}\text { Sampling at second } \\
\text { stage }\end{array}$ & $\begin{array}{l}\text { Randomly selected start point, } \\
\text { then every second household }\end{array}$ & $\begin{array}{l}\text { Systematic random sampling } \\
\text { from list }\end{array}$ & NA & $\begin{array}{l}\text { Systematic random sampling } \\
\text { from list }\end{array}$ & NA \\
\hline Fieldwork dates & 22 May to 5 August 2003 & $\begin{array}{l}16 \text { October to } 24 \text { December } \\
2003\end{array}$ & $\begin{array}{l}16 \text { December } 2003 \text { to } 25 \\
\text { February } 2004\end{array}$ & 19 May to 21 December 2005 & 13 January to 8 April 2006 \\
\hline Interviewers & $\begin{array}{l}10 \text { SEWA Insurance } \\
\text { interviewers }\end{array}$ & $\begin{array}{l}10 \text { SEWA Insurance } \\
\text { interviewers }\end{array}$ & $\begin{array}{l}20 \text { district based, SEWA rural } \\
\text { development interviewers }\end{array}$ & $\begin{array}{l}10 \text { SEWA Insurance } \\
\text { interviewers }\end{array}$ & 10 SEWA Insurance interviewers \\
\hline $\begin{array}{l}\text { Criteria for counting } \\
\text { household as absent }\end{array}$ & $\begin{array}{l}\text { No Hh member present on day } \\
\text { of first (and only) visit }\end{array}$ & $\begin{array}{l}\text { No Hh member contacted after } \\
\text { two visits separated by } \\
\text { minimum of } 24 \text { hours }\end{array}$ & $\begin{array}{l}\text { No Hh member contacted after } \\
\text { two visits separated by } \\
\text { minimum of } 24 \text { hours }\end{array}$ & $\begin{array}{l}\text { No Hh member contacted after } \\
\text { two visits separated by } \\
\text { minimum of } 24 \text { hours }\end{array}$ & $\begin{array}{l}\text { No Hh member contacted after } \\
\text { two visits separated by } \\
\text { minimum of } 24 \text { hours }\end{array}$ \\
\hline Achieved sample size & $784(98 \%)$ & 967 (81\%) & $674(95 \%)$ & $1072(89 \%)$ & $1326(92 \%)$ \\
\hline $\begin{array}{l}\text { Reasons for "non- } \\
\text { response" }\end{array}$ & $\begin{array}{l}\text { Refused interview, } n=1(6 \%) \text {; all } \\
\text { Hh members absent, } n=15 \\
(94 \%)\end{array}$ & $\begin{array}{l}\text { Hh moved/not found, } n=202 \\
(87 \%) ; \text { all Hh members absent, } \\
n=31(13 \%)\end{array}$ & $\begin{array}{l}\text { Refused interview, } n=2(5 \%) ; \\
\text { Hh moved/not found, } n=27 \\
(69 \%) ; \text { all Hh members absent, } \\
n=10(26 \%)\end{array}$ & $\begin{array}{l}\text { Hh moved/not found, } n=72 \\
(56 \%) ; \text { all Hh members absent, } \\
n=56(44 \%)\end{array}$ & $\begin{array}{l}\text { Hh moved/not found, } n=55 \\
\text { ( } 48 \%) ; \text { all Hh members absent, } \\
n=59(52 \%)\end{array}$ \\
\hline
\end{tabular}

Hh=household; NA=not applicable; PPS=probability proportional to size; SEWA=Self Employed Women's Association. 

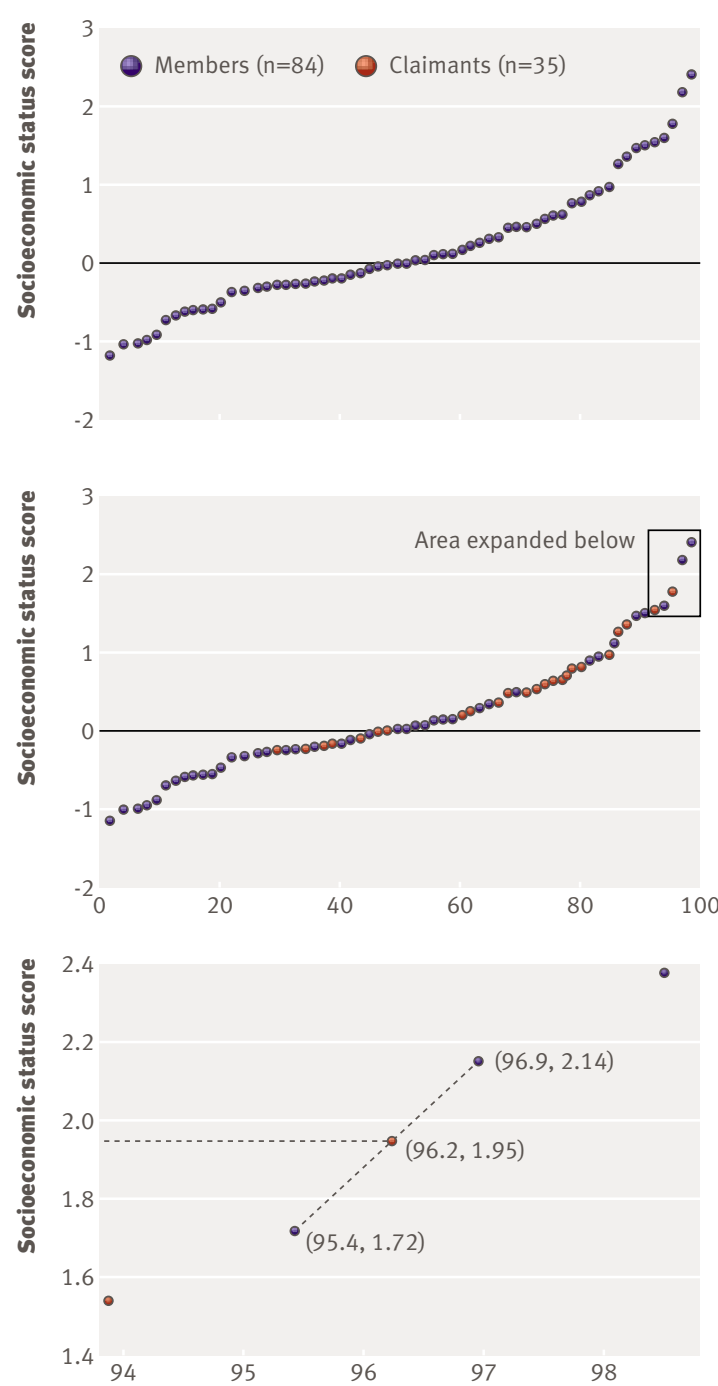

Within cluster centiles of socioeconomic status

Fig 1 | Within cluster rank versus untransformed socioeconomic index value for members (top) and members plus claimants (middle); illustration of linear interpolation of within cluster centile of socioeconomic status for one claimant (bottom) (Bayad sub-district, 2003)

and elsewhere, given the widespread inequities in use of health services. ${ }^{216}$ The Indian health system has characteristics that make it less accessible to poor people, including user fees; stigmatisation by medical staff; and a paucity of health workers, clinics, and hospitals where poor people live, in rural areas and urban slums. ${ }^{15}$ Removing such supply-side barriers is difficult for non-governmental organisations, given their limited financial resources and the complete absence of regulatory checks and balances to guide and support them in rehabilitating the healthcare system. ${ }^{31}$ Community based organisations can, however, tackle select social, economic, and cultural factors that prevent people from seeking health care. Great interest exists in evaluating the impact of such interventions on disease prevention and access to health care in India and elsewhere. ${ }^{32-34}$
To reduce contamination, we randomised the trial at the level of sub-districts, an existing administrative unit. We considered sub-districts for inclusion if they had 500 or more female SEWA Insurance members aged 18 or above in 2003 . Out of the 27 sub-districts that met this criterion, we excluded those in which all members were mandatorily enrolled in the scheme by a donor agency (three sub-districts) or which had no general hospital of 25 beds or more (one sub-district). Of the remaining 23 sub-districts, we selected the 16 with the highest number of female SEWA Insurance members. These sub-districts spanned a large agricultural area in the north of Gujarat state.

Within the selected sub-districts, the interventions were to be delivered to all female and male members of SEWA Insurance for 2004 and 2005. The only members excluded from the interventions were those for whom address data were so incomplete that district, sub-district, or village could not be determined (approximately $3.5 \%$ of members in the 2004 database) and those for whom address data seemed to be complete but who could not be found at the village level $(<1 \%$ to $8 \%$, by sub-district, in 2004$)$.

We randomly allocated four study sub-districts to each of after sales service and supportive supervision, prospective reimbursement, both, and standard scheme (control). Interventions were launched on 1 August 2004. The first trial related visits to SEWA Insurance member households in the three intervention areas were made between August and December 2004. Interventions continued to the end of 2005 .

The primary outcome measure was the socioeconomic status of claimants relative to the membership base in their sub-districts of residence; detailed description of this measure can be found elsewhere. ${ }^{24}$ Just before the beginning of the trial, a representative survey of the general rural population from which SEWA Insurance draws its members gathered data on a wide range of potentially relevant markers of socioeconomic status (table 2). ${ }^{35}$ We then developed a summary index of socioeconomic status for this population by using survey data, principal components analysis, and methods described by Henry and colleagues. ${ }^{35}$ Subsequently, at baseline and again postintervention, we determined the distribution of socioeconomic status among SEWA Insurance members by representative surveys of members' households in the 16 trial sub-districts. We ranked the membership base in each sub-district according to socioeconomic status, so that the poorest household ranked zero, the wealthiest 100 , and the median household 50 (fig 1, top panel).

Interviews with members of claimants' households before and after the intervention enabled a sub-district specific rank score for each claimant's household to be calculated (table 2), on the basis of the same socioeconomic variables and index described in the previous paragraph. For these households, we converted socioeconomic index values into sub-district specific rank scores (on a scale of 0-100) by linear interpolation based on the rank of the members' households with the closest (that is, the next lowest and the next highest) 


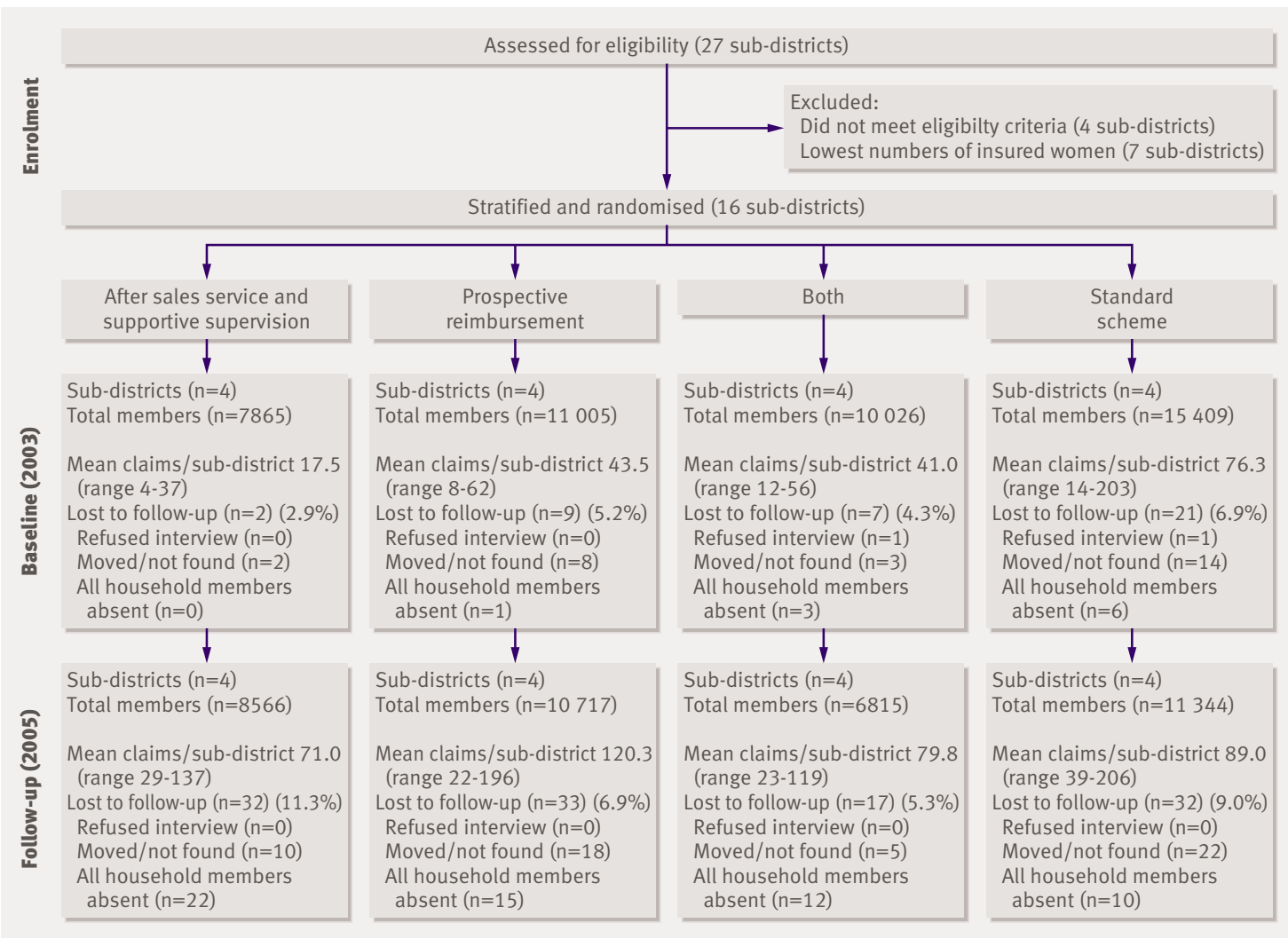

Fig 2 | Number of clusters and participants randomly assigned, receiving intended intervention, and analysed for primary outcome

socioeconomic index values (fig 1 , middle and bottom panels). We assigned rank scores of 0 and 100 to claimants whose socioeconomic index values were lower or higher than those of any sampled member in the same sub-district.

Secondary outcomes were rates of enrolment in SE WA Insurance, mean socioeconomic status of the insured population relative to the general rural population, and rate of submission of claims.

\section{Statistical analysis}

We calculated the required sample size for the trial on the basis of the primary study outcome and took into account the intracluster (sub-district) correlation, the mean socioeconomic status rank score of claimants relative to scheme members at baseline, and the intracluster variance of this parameter. ${ }^{36}$ We determined that the minimal effect to be detected as statistically significant would be a reduction of 20 points in the mean socioeconomic status rank score of the claimants relative to scheme members (that is, from 60 to 40). Power was set at $90 \%$ and statistical significance at $5 \%$, with two sided testing throughout. This calculation suggested a minimum of four clusters per intervention arm.

We stratified sub-districts by mean socioeconomic status of claimants (relative to members) in order to minimise imbalance across the intervention groups. Within each of four strata, we randomly assigned subdistricts to an intervention or standard scheme by drawing one of four differently coloured balls from a bag. Each colour represented one of the three intervention groups or the standard scheme. The balls were drawn without replacement. SEWA Insurance staff did the random assignment, so that they would understand the process and perceive the allocation as fair. Staff were aware of the sub-district that was being allocated but were blind to the interventions being drawn because they could not see into the bag or feel any difference between balls.

The trial was "open" in so far as neither the participants nor the personnel could be blinded to intervention assignment after randomisation. We sought to minimise bias by training interviewers to administer the surveys in a uniform manner across intervention groups and by close supervision.

The analytic strategy was that recommended by Murray for a cluster randomised trial with a repeated cross section (pre-test, post-test) design with a control group. ${ }^{37}$ With all the data pooled, the expected value of the outcome indicator $\mathrm{Y}$ can be expressed, in a regression framework, as:

\section{$\mathrm{Y}=\alpha+\beta 1$.TREATMENT_GROUP+ $\beta 2$. TIME $+\beta 3$. TREATMENT_GROUP $\times$ TIME}

where TIME is a dummy variable coded $0=$ baseline, $1=$ postintervention. This equation is a simplified representation, as three indicator variables rather than just one represented the different intervention groups (in 
each case contrasted with the standard scheme group), and three interactions with time captured the net change in each treatment group or "impact" of the programme. We used a mixed effects regression model in SAS to estimate all coefficients, by using the approach of Kenward and Roger to estimate the relevant degrees of freedom for the statistical tests. ${ }^{38}$

\section{RESULTS}

All 16 clusters randomised at baseline were retained at follow-up (fig 2). A small percentage of interviews were unsuccessful both in the pre-intervention survey (2.9$6.9 \%$ per group) and in the postintervention survey (5.3-11.3\%), primarily because the family was absent from home at successive visits or the interviewer was unable to locate the household.

At baseline, the four treatment groups were very similar with respect to the primary outcome measure, the mean socioeconomic status of claimants relative to members in the same sub-district (table 3). Secondary outcome indicators, on the other hand, were quite variable between groups: enrolment rates were 26.7-52.6/ 1000 general population, socioeconomic status of members relative to the general population was 41.651.2 per group, and submission rates for hospital admission claims were 8.9-19.2/1000 members per group. The standard scheme group had more "best" values with respect to the four outcome indicators than any other group, and the after sales service group had "worst" values for three out of four outcome indicators. The four groups also differed somewhat in terms of their total population and population density but were fairly similar with respect to the percentage of the population that was female and literate. Members' characteristics varied: the percentage of women who had also enrolled their spouse was 15.6-35.5\% per intervention group and the percentage of women who paid by fixed deposit was 6.6-19.3\% per group.

Rates of coverage of the interventions were high (table 4). In after sales service and "both" areas, for example, $96.3 \%$ and $97.8 \%$ of respondents reported receiving the reminder wall piece. In prospective reimbursement and "both" areas, $82.1 \%$ and $85.6 \%$ of respondents reported receiving the silver identity card needed for receipt of reimbursement in hospital. The silver card seemed to be less memorable than the reminder wall piece: they were distributed together in the "both" sub-districts, yet a higher percentage of members recalled the latter. Leakage of the interventions was minimal.

After the intervention, respondents in the intervention areas were no more knowledgeable about SEWA Insurance than those in the standard scheme area (table 4). That is, the interventions did not seem to have any significant impact on knowledge, as assessed by this survey.

The survey of claimants showed that members in different intervention areas differed significantly in terms of how they first notified SEWA Insurance of their claim (table 4). In prospective reimbursement and "both" areas, claimants were 25.4-27.0 percentage points more likely than those in the standard scheme areas to have first notified SEWA Insurance of their claim by calling from the hospital before discharge. Claimants rarely used the postcards to notify SEWA Insurance of their claim.

Between 2003 and 2005, the mean socioeconomic status of SEWA Insurance members (relative to the

\begin{tabular}{|c|c|c|c|c|}
\hline & Standard scheme & $\begin{array}{l}\text { After sales } \\
\text { service }\end{array}$ & $\begin{array}{l}\text { Prospective } \\
\text { reimbursement }\end{array}$ & Both \\
\hline \multicolumn{5}{|l|}{ Primary and secondary outcome indicators at baseline } \\
\hline SES of claimants relative to members in same sub-districts & $58.8(12.8)$ & $58.9(11.3)$ & $56.4(8.5)$ & $57.1(10.9)$ \\
\hline Enrolment rate (per 1000 population aged $18-55$ years) & $43.8(55.7)$ & $52.6(85.9)$ & $26.7(15.9)$ & $35.1(27.7)$ \\
\hline SES of scheme members relative to rural population & $41.6(4.8)$ & $51.2(6.2)$ & $49.1(6.6)$ & $42.0(3.3)$ \\
\hline $\begin{array}{l}\text { Rate of hospital admission claim submission (per } 1000 \text { members } \\
\text { per nine months) }\end{array}$ & $19.2(11.9)$ & $8.9(6.0)$ & $18.4(11.2)$ & $17.4(9.0)$ \\
\hline \multicolumn{5}{|l|}{ Member factors at baseline $†$} \\
\hline Percentage households in which spouse is also covered & $19.4(6.49)$ & $24.5(14.1)$ & $35.5(25.7)$ & $15.6(10.1)$ \\
\hline Percentage women, fixed deposit & $10.2(3.92)$ & $19.3(10.3)$ & $6.6(6.15)$ & $11.4(5.60)$ \\
\hline \multicolumn{5}{|l|}{ Sub-district factors at baselineł } \\
\hline Number & 4 & 4 & 4 & 4 \\
\hline Total population: & 1105405 & 996265 & 1037084 & 664835 \\
\hline Percentage female & $47.7(0.437)$ & $47.8(0.751)$ & $47.9(0.278)$ & $48.6(1.43)$ \\
\hline Percentage literate, (aged $>6$ years): & $65.3(19.2)$ & $62.4(18.4)$ & $67.6(8.42)$ & $64.1(11.8)$ \\
\hline Female literacy & $51.6(21.0)$ & $49.6(17.5)$ & $52.8(10.8)$ & $50.8(12.5)$ \\
\hline Male literacy & 77.9 (17.5) & $74.2(19.3)$ & $81.4(6.38)$ & $76.8(11.2)$ \\
\hline Population density, people $/ \mathrm{km}^{2}$ & $635(432)$ & $255(219)$ & $440(500)$ & 439 (383) \\
\hline
\end{tabular}

SES=socioeconomic status.

* Means for each intervention group are unweighted average of four relevant sub-district level means.

†2003 scheme membership figures.

fData from 2001 population census. 
rural population of Gujarat) rose significantly, on average by 6.9 on the 100 point scale $(\mathrm{P}<0.001)$ (table 5). No association existed, however, between the interventions and either changes in the enrolment rate or the change in socioeconomic status of members. Rates of claims increased significantly, on average by 21.6 per 1000 members $(\mathrm{P}<0.001)$. However, differences between the intervention groups and the standard scheme were not significant. Neither time nor interventions had any systematic effect on the socioeconomic status of claimants relative to members in the same sub-district.

\section{DISCUSSION}

This trial shows that, in a community based insurance scheme in rural Gujarat, neither switching from reimbursement to upfront payment nor strengthening contacts between members and administrators was sufficient to ensure that the poorer members in each sub-district were able to enjoy the greater share of the scheme benefits. Instead, the rate of claims increased across the study area. This was in spite of the fact that we achieved high rates of coverage with our interventions, with virtually no leakage from intervention to standard scheme areas. The interventions themselves were designed on the basis of extensive qualitative research about the barriers that might prevent poor members making a successful claim. ${ }^{29}$

\section{Strengths and limitations}

Our trial was based on a small number of randomisation units (sub-districts) in each intervention group. However, on the basis of the standard errors of the estimated impacts of the interventions, we could have detected as statistically significant an average change in the socioeconomic status score of claimants relative to members in the same sub-district of just 16 points- an even smaller change than the 20 point change we initially set out to detect. The trial was therefore not underpowered on the primary outcome.

On the other hand, the trial does seem to have had disappointingly low power with respect to the secondary outcomes. Large increases in rates of claims occurred in 11/12 intervention sub-districts, compared with only $1 / 4$ standard scheme sub-districts (fig 3), but these contrasts were not statistically significant if analysed intervention group by intervention group as the study protocol demanded (table 5). We note, however, that both interventions involved making individual contact with members in their homes, and we are inclined to believe that this feature of the interventions had a greater impact than elements unique to either specific intervention, such as the postcard, enhanced supervision, or reimbursement before discharge from hospital. Qualitative interviews, not documented here, revealed that members greatly appreciated the home visits, even though our postintervention survey suggested that the visits did not increase members' knowledge about the scheme's benefits or processes. The house to house visits may have increased submission of claims by increasing members' trust in the scheme or by increasing some aspect of their knowledge that was not captured by the postintervention survey, such as the identity of the local aagewan.

An additional limitation of the trial may have been the short period allowed for implementation and then stabilisation of the interventions. When we started to monitor the primary outcome, the interventions had been running for a maximum of eight months (1 August 2004 to 1 April 2005). Although most of the key intervention functions were implemented within that period, improvements could have been made had there been more time. We do not think a longer implementation period would have increased the interventions' impact

Table 4 | Implementation and use of interventions

\begin{tabular}{|c|c|c|c|c|c|}
\hline \multirow[b]{2}{*}{ Indicators } & \multirow{2}{*}{$\begin{array}{l}\text { Control } \\
\text { group }\end{array}$} & \multirow[b]{2}{*}{ Any intervention effect? } & \multicolumn{3}{|c|}{ Point estimate in intervention groups, relative to control } \\
\hline & & & After sales service & Prospective reimbursement & Both \\
\hline \multicolumn{6}{|l|}{ Coverage and leakage } \\
\hline Received reminder wall piece & $0 \%$ & Yes; P<0.0001 & $96.3 \%$ \%** $(94.0 \%$ to $98.7 \%)$ & $0.4 \%(-2.0 \%$ to $2.7 \%)$ & 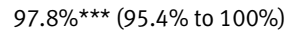 \\
\hline Received postcard & $0 \%$ & Yes; P<0.0001 & $85.3 \%$ *** $(79.8 \%$ to $90.8 \%)$ & $0.4 \%(-5.1 \%$ to $5.9 \%)$ & $84.9 \% * \star \star ~(79.4 \%$ to $90.4 \%)$ \\
\hline Received silver prospective & $0 \%$ & Yes; $P<0.0001$ & $0.4 \%(-6.2 \%$ to $7.0 \%)$ & 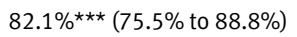 & 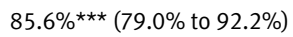 \\
\hline
\end{tabular}

reimbursement card

Knowledge about SEWA Insurance $†$

\begin{tabular}{|c|c|c|c|c|c|}
\hline Know that they are currently insured & $93.5 \%$ & No; $P=0.4357$ & NA & NA & NA \\
\hline Know hospital admission is covered & $81.8 \%$ & No; $P=0.1893$ & NA & NA & NA \\
\hline Know ceiling is 2000 rupees & $25.1 \%$ & No; $P=0.4448$ & NA & NA & NA \\
\hline Know delivery is not covered & $35.6 \%$ & No; $P=0.0916$ & NA & NA & NA \\
\hline Correct out of three vignettes & 1.30 & No; $P=0.8295$ & NA & NA & NA \\
\hline \multicolumn{6}{|c|}{ Use of prospective reimbursement and postcard $\ddagger$} \\
\hline Called from hospital & $2.9 \%$ & Yes; $P=0.0133$ & $0.8 \%(-19.1 \%$ to $20.7 \%)$ & $25.4 \% *(5.6 \%$ to $45.2 \%)$ & $27.0 \% *(7.2 \%$ to $46.9 \%)$ \\
\hline Submitted postcard & $0 \%$ & Yes; $P=0.0008$ & 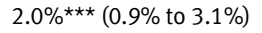 & $0 \%(-1.0 \%$ to $1.0 \%)$ & $0.3 \%(-0.7 \%$ to $1.4 \%)$ \\
\hline
\end{tabular}

$\mathrm{NA}=$ not applicable; SEWA=Self Employed Women's Association.

${ }^{\star} \mathrm{P}<0.05$.

$\star \star \star P<0.001$.

†Results on members' knowledge of non-health benefits not reported.

†Means of first notifying SEWA Insurance about claim. 


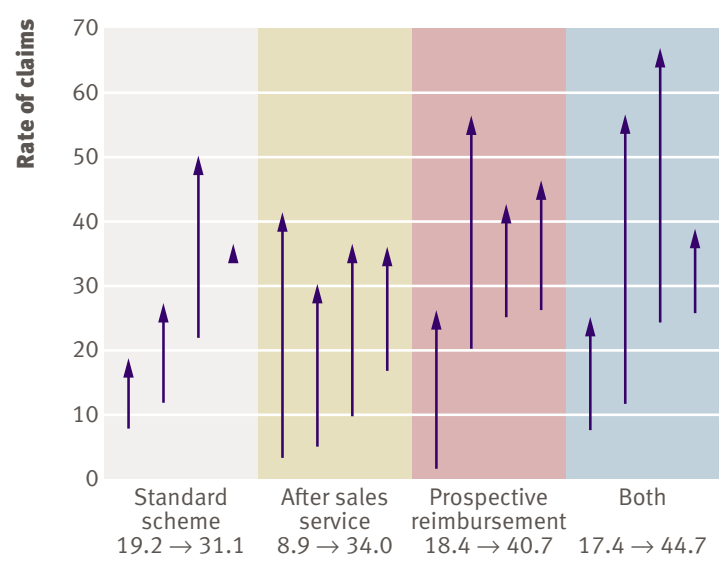

Fig 3 | Increase in rate of claims between 2003 (tail of arrow) and 2005 (head of arrow) by intervention group and subdistrict

on the primary outcome measure, but it may have resulted in a greater (and possibly statistically significant) increase in the impact on claim rate.

We believe that our trial is methodologically highly innovative. As far as we are aware, it is one of the first cluster randomised trials to use an equity outcome and to evaluate a health financing intervention in a developing country. The summary index of socioeconomic status used to characterise both claimants and members is simple and transparent, has a strong theoretical basis and a systematic approach to indicator selection, and is locally appropriate-incorporating variables that are important indicators of socioeconomic status in a particular study setting - and the corresponding survey instrument can be easily and quickly administered ${ }^{39}$ Also, the primary outcome measure used (the socioeconomic status rank score) is simple to interpret because it varies on a scale from 0 to 100 , with 50 indicating an equity neutral outcome, and is efficient because it draws on data from claimants and members at all levels of socioeconomic status.

The cluster randomised design brings both advantages and disadvantages. The study has strong internal validity, and we used qualitative methods both at baseline and during implementation of the interventions to understand the processes at work. ${ }^{2829}$ Relevance to other settings, or external validity, depends on understanding the context of the insurance programme and the factors that influence its operation, including aspects such as physical access to health services that we were not able to cover in the trial. Basing the study within the research cell of SEWA and involving SEWA staff in the research, plus the expertise of the external researchers in community based health insurance in India and elsewhere, meant that the team had indepth knowledge of both SEWA and community based health insurance schemes elsewhere, so the relevance of study findings to other settings could be assessed, in so far as the state of knowledge on community based health insurance permits. ${ }^{40}$

\section{Policy implications}

The lack of equity impact in our trial may have resulted from a variety of factors. Firstly, the interventions did not tackle barriers such as distance to hospital, transportation costs, and the opportunity costs of hospital admission, especially for female members with many household responsibilities. Secondly, the interventions were more effective than anticipated among less poor members, suggesting that barriers faced by the poorest people in seeking hospital admission and submitting a claim were just as relevant to the less poor members. Thirdly, although the interventions were designed to meet the specific needs of the poorest members, we had no way of delivering them selectively to these people as it was logistically and ethically impossible to separate the poorest members from the less poor ones during delivery of the interventions.

SEWA Insurance is continuing and extending the interventions because of their perceived and projected benefits, including the increased rate of claims. The rural claims rate is now close to that of Ahmedabad City (51 per 1000 members over nine months in 2005), reducing urban-rural inequities. Scheme administrators believe that over a longer period the interventions will lead to higher rates of retention and enrolment, by enhancing members' trust in and satisfaction with the scheme. Future studies should design and test other interventions to make the scheme more equitable.

More broadly, this study feeds into a small but developing literature on whether and how community based health insurance can benefit the poorest people. SEWA insurance has some unusual features, including its base in an organisation of which the prime goals are to organise female workers to achieve work security, income security, food security, and social security and

Table 5 | Time effect and intervention effect $\dagger$

Indicators

Members per 1000 population

SES of members (relative to population)

Claims submission per 1000 members (nine months)

SES of claimants (relative to members)

$\mathrm{SES}=$ socioeconomic status.

$\star \star * P<0.001$.

†Impacts expressed as absolute changes; point estimates, $95 \%$ confidence intervals, and P values derived from mixed effects regression models relating each outcome to intervention group, time, and the interaction of the two, accounting appropriately for clustering within intervention areas and within sub-districts. 


\section{WHAT IS ALREADY KNOWN ON THIS TOPIC}

Community based health insurance is often cited as a means of improving access to health care and financial protection in developing countries

The scope for equitable redistribution of resources by such schemes may be limited by small membership, exclusion of the poorest people, and inequitable utilisation of benefits

No previous study has evaluated strategies for improving the uptake of benefits of a community based health insurance scheme by its poorest members

\section{WHAT THIS STUDY ADDS}

Neither switching from reimbursement to upfront payment nor strengthening contacts between members and administrators was sufficient to ensure that poorer members were able to enjoy the greater share of the scheme's benefits

to make women individually and collectively self reliant, economically independent, and capable of making their own decisions. This contrasts with an alternative approach to community based health insurance, in which a single purpose organisation is formed to provide insurance. The relative merits of different organisational and management approaches to community based health insurance need to be explored further.

Contributors: MKR and TS participated in the study's conception and design, acquisition of data, analysis and interpretation of data, and drafting the article. MC and AJM participated in the study's conception and design and critically revising the article for important intellectual content. FG, RJ, and FP participated in the acquisition of data and critically revising the article for important intellectual content. SSM participated in the study's conception and design, analysis and interpretation of the data, and critically revising the article for important intellectual content. MKR is the guarantor.

Funding: Wellcome Trust (UK).

Competing interests: None declared.

Ethical approval: Executive Committee of the Self-Employed Women's Association (Ahmedabad, Gujarat) and Ethics Committee of the London School of Hygiene and Tropical Medicine.

1 Gwatkin DR, Rustein S, Johnson K, Pande RP, Wagstaff A. Socioeconomic differences in health, nutrition and population in India. Washington, DC: World Bank, 2000.

2 Wagstaff A. Poverty and health sector inequalities. Bull World Health Organ 2002;80:97-105.

3 Makinen M, Waters H, Rauch M, Almagambetova N, Bitran R, Gilson L, et al. Inequalities in health care use and expenditures: empirical data from eight developing countries and countries in transition. Bull World Health Organ 2000;78:55-65.

4 Xu K, Evans DB, Kawabata K, Zeramdini R, Klavus J, Murray CJL. Household catastrophic health expenditure: a multicountry analysis. The Lancet 2003;362:111-7.

5 Schieber G, Baeza C, Kress D, Maier M. Financing health systems in the 21st century. In: Jamison DT, Breman JG, Measham AR, Alleyne G, Claeson M, Evans DB, et al, eds. Disease control priorities in developing countries. 2nd ed. New York: Oxford University Press, 2006:1401.

6 World Health Organization. The world health report 2000-health systems: improving performance. Geneva: WHO, 2000

7 International Labour Office (Universitas Programme). Extending social protection in health through community based health organizations: evidence and challenges. Geneva: ILO, 2002:79.

8 Ekman B. Community-based health insurance in low-income countries: a systematic review of the evidence. Health Policy Plan 2004;19:249-70.

9 Bennett S, Creese A, Monasch R. Health insurance schemes for people outside formal sector employment. Geneva: Division of Analysis, Research and Assessment, World Health Organization, 1998.

10 Jakab M, Preker A, Krishnan C, Schneider P, Diop F, Jutting J, et al. Analysis of community financing using household surveys. In: Preker A, Carrin G, eds. Health financing for poor people: resource mobilization and risk sharing. Washington, DC: World Bank, 2004:201-30.

11 Criel B, Van der Stuyft P, Van Lerberghe W. The Bwamanda hospital insurance scheme: effective for whom? A study of its impact on hospital utilization patterns. Soc Sci Med 1999;48:897-911.
12 Schneider P, Hanson K. Horizontal equity in utilisation of care and fairness of health financing: a comparison of micro-health insurance and user fees in Rwanda. Health Econ 2006;15:19-31.

13 Dror DM, Koren R, Steinberg DM. The impact of filipino micro healthinsurance units on income-related equality of access to healthcare. Health Policy 2006;77:304-17.

14 World Health Organization. Working together for health: the world health report 2006. Geneva: WHO, 2006.

15 Peters DH, Yazbeck AS, Sharma RR, Ramana GNV, Pritchett LH, Wagstaff A. Better health systems for India's poor: findings, analysis, and options. Washington DC: World Bank, 2002.

16 Mahal A, Singh J, Afridi F, Lamba V, Gumber A, Selvaraju V. Who benefits from public health spending in India? New Delhi: National Council of Applied Economic Research (NCAER), World Bank, 2000.

17 Matthies S, Cahill KR. Lessons from across the World: how India can break barriers to develop health insurance. IRDA Journal 2004;II (11):7-12.

18 Gupta I, Trivedi M. Social health insurance redefined: health for all through coverage for all. Econ Polit Wkly 2005;Sept 17:4132-40.

19 Ministry of Health and Family Welfare. National health policy 2002 New Delhi: MoHFW, Government of India, 2002.

20 Ranson MK. Community-based health insurance schemes in India: a review. Natl Med I India 2003;16:79-89.

21 Devadasan N, Ranson MK, Van Damme W, Acharya A, Criel B. The landscape of community health insurance in India: an overview based on 10 case studies. Health Policy 2006;78:224-34.

22 Ranson MK. Reduction of catastrophic health care expenditures by a community-based health insurance scheme in Gujarat, India: current experiences and challenges. Bull World Health Organ 2002;80:613-21.

23 Victora CG, Habicht JP, Bryce J. Evidence-based public health: moving beyond randomized trials. Am J Public Health 2004;94:400-5.

24 Morris SS, Ranson MK, Sinha T, Mills AJ. Measuring improved targeting of health interventions to the poor in the context of a community-randomised trial in rural India. Contemp Clin Trials 2006; Oct 14 doi:10.1016/j.cct.2006.10.008.

25 Hawe P, Shiell A, Riley T, Gold L. Methods for exploring implementation variation and local context within a cluste randomised community intervention trial. J Epidemiol Community Health 2004;58:788-93.

26 Oakley A, Strange V, Bonell C, Allen E, Stephenson J. Process evaluation in randomised controlled trials of complex interventions. BMJ 2006;332:413-6.

27 Rothwell PM. External validity of randomised controlled trials: "to whom do the results of this trial apply?" Lancet 2005;365:82-93.

28 Ranson MK, Sinha T, Chatterjee M, Acharya A, Bhavsar A, Morris SS, et al. Making health insurance work for the poor: learning from the Self-Employed Women's Association's community-based health insurance scheme. Soc Sci Med 2006;62:707-20.

29 Sinha T, Ranson MK, Chatterjee M, Acharya A, Mills A. Barriers faced by the poor in benefiting from community-based insurance services: lessons learnt from SEWA Insurance, Gujarat. Health Policy Plan 2006;21:132-42.

30 Hawe P, Shiell A, Riley T. Complex interventions: how "out of control" can a randomised controlled trial be? BMJ 2004;328:1561-3.

31 Bhat R. Regulation of the private health sector in India. Int J Health Plann Manage 1996;11:253-74.

32 Ghosh SK, Patil RR, Tiwari S, Dash AP. A community-based health education programme for bio-environmental control of malaria through folk theatre (Kalajatha) in rural India. Malar J 2006;5:123.

33 Gwatkin DR, Wagstaff A, Yazbeck A, eds. Reaching the poor with health, nutrition and population services: what works, what doesn't, and why. Washington, DC: World Bank, 2005.

34 World Bank. World development report 2006: equity and development. Washington, DC: World Bank (and Oxford University Press), 2005.

35 Henry C, Sharma M, Lapenu C, Zeller M. Assessing the relative poverty of microfinance clients: a CGAP operational tool. Washington, DC: International Food Policy Research Institute, 2000.

36 Hayes RJ, Bennett S. Simple sample size calculation for clusterrandomized trials. Int J Epidemiol 1999;28:319-26.

37 Murray DM. Design and analysis of group-randomized trials. New York: Oxford University Press, 1998.

38 Kenward MG, Roger JH. Small sample inference for fixed effects from restricted maximum likelihood. Biometrics 1997;53:983-97.

39 Morris SS. Epidemiology and the study of socio-economic inequalities in health. In: INDEPTH Network, ed. Measuring health equity in small areas-findings from demographic surveillance systems. Aldershot, UK: Ashgate, 2005:1-18.

40 Task Force on Health Systems Research. Informed choices for attaining the millennium development goals: towards an international cooperative agenda for health-systems research. Lancet 2004:364:997-1003.

Accepted: 20 March 2007 